\title{
Electrochemical deposition of Zinc on mild steel
}

\author{
Asmae El Fazazi, Moussa Ouakki * and Mohamed Cherkaoui \\ Laboratory of Materials Engineering and Environment (LMEE), Faculty of Sciences, University Ibn Tofail, \\ BP 133, 14000 Kenitra, Morocco
}

\begin{abstract}
Zn coating electrodeposited on a mild steel substrate in an acid bath was investigated using cyclic voltammetric and chronopotentiometry techniques. The effect of the current density on the deposition potential, the thickness of the deposit, deposition rate and current efficiency was investigated. The chemical composition and surface morphology of Zn coatings are characterized using Energy Dispersive X-Ray (EDX) spectrometer and Scanning Electron Microscopy (SEM), respectively. SEM observations indicated that the morphology of the film surface was modified from dense and uniaxial to disperse and dendritic with increasing the current density. The EDX analyses revealed the presence of $\mathrm{Zn}$ and $\mathrm{O}$ in the deposit.
\end{abstract}

Keywords: Zinc electrodeposition; cyclic voltammetry; current density; SEM; EDX.

\section{Introduction}

There are many technological processes to elaborate metallic thin films. Electrodeposition is the most commonly used one due to technical and environmental advantages. The electrochemical deposition method has some considerable benefits such as low-cost, convenience and allows for controlling of multiple experimental parameters. Improved performance of the electrodeposited coatings mainly depends on the controlled deposition parameters, such as temperature, $\mathrm{pH}$ value, electrolyte composition, potential, current density, concentrations of ions, the use of additives and stirring. Zn coatings are widely used in industry, not only because $\mathrm{Zn}$ is anodic to steel and thus sacrificially protects the base metals but also owing to its low cost and natural abundance. The deposition of Zn coatings usually relies upon the electrodeposition technique in an acidic or alkaline medium ${ }^{1,2}$.

Zn coatings are extensively electrodeposited from acidic electrolytes. Thus, a simple electrolyte bath was developed by Sriraman et al. ${ }^{3}$ containing $\mathrm{KCl}$ as carrier electrolyte (The function of $\mathrm{KCl}$ is to increase the electrical conductivity and reduce the viscosity of the bath) ${ }^{4}$, and $\mathrm{H}_{3} \mathrm{BO}_{3}$ as a buffer, which exhibits good results to inhibit both hydrogen formation by acting as a buffer and/or adsorbing at the electrode surface to block then the active centers ${ }^{5-7}$.

The present work aims to investigate $\mathrm{Zn}$ electrodeposition from a simple free additives bath on mild steel. The electrochemical process was examined by cyclic voltammetry (CV) and chronopotentiometry. The effect of plating current

*Corresponding author: Moussa Ouakki

Email address: moussassaw@gmail.com

DOI: http://dx.doi.org/10.13171/mjc8119021318mo density on the chemical composition and the surface morphology of $\mathrm{Zn}$ coatings has been investigated, and the deposits were characterized by analyzing their morphology and composition using Scanning Electron Microscopy (SEM) and Energy Dispersive $\mathrm{X}$-Ray (EDX), respectively.

\section{Experimental details}

The electrochemical measurements were carried out using Potentiostat/Galvanostat/Voltalab PGZ 100 monitored by a computer (Voltamaster 4 Software). The voltammetric measurements were performed in the potential range between $-0.3 \mathrm{~V}$ and $-2 \mathrm{~V}^{5}$.

A three-electrode electrochemical cell was employed with a working electrode of steel plate, having a surface area of $1 \mathrm{~cm}^{2}$, a Pt counter electrode placed in a separate compartment and an $\mathrm{Ag} / \mathrm{AgCl} / \mathrm{KCl}$ saturated reference electrode.

Plates of E24 steel with a nominal chemical composition of $99.732 \%$ wt Fe, $0.17 \%$ wt C, $0.045 \%$ wt $\mathrm{P}, 0.045 \%$ wt Sand $0.008 \%$ wt N were used as the substrate. Before $\mathrm{Zn}$ plating, the substrates were mechanically

they are prepared using abrasive emery papers down to 2000 grit, decreased in ethanol at room temperature and finally rinsed with distilled water and immediately transferred to the electroplating bath.

The baths compositions are presented in Table 1. Analytical grade chemicals and distilled water were used for the preparation of the electrolyte. The $\mathrm{pH}$ was adjusted at 4.5 by adding $1 \mathrm{M} \mathrm{HCl}$ or $1 \mathrm{M} \mathrm{NaOH}$

Received November 3, 2018

Accepted November 22, 2018

Published February 13, 2019 
solutions, and the temperature is set at ambient temperature $20 \pm 1{ }^{\circ} \mathrm{C}$. A current density of either $16 \mathrm{~mA} . \mathrm{cm}^{-2}, 24 \mathrm{~mA} . \mathrm{cm}^{-2}, 32 \mathrm{~mA} . \mathrm{cm}^{-2}$ or $40 \mathrm{~mA} . \mathrm{cm}^{-2}$ was applied for $20 \mathrm{~min}$.
The electrodeposited surface morphologies of the coated samples, along with the chemical composition were examined using a Scanning Electron Microscopy (Quanta FEG 450) coupled with Energy Dispersive X-Ray (EDX) spectrometer and fulfilled in UATRS-CNRST-Rabat.

Table 1. Baths composition.

\begin{tabular}{|c|c|c|c|}
\hline Electrolytes & $\mathrm{ZnSO}_{4}, 7 \mathrm{H}_{2} \mathrm{O}\left(\mathrm{g} . \mathrm{l}^{-1}\right)$ & $\mathrm{H}_{3} \mathrm{BO}_{3}\left(\mathrm{~g} . \mathrm{l}^{-1}\right)$ & $\mathrm{KCl}\left(\mathrm{g} . \mathrm{l}^{-1}\right)$ \\
\hline 1 & - & - & 93.2 \\
\hline 2 & - & 24.8 & 93.2 \\
\hline 3 & 64.6 & 24.8 & 93.2 \\
\hline
\end{tabular}

\section{Results and Discussion}

\section{Electrochemical study}

Fig.1 shows the voltammogram realized in electrolyte 1 . We note that the current density is fully stable between $-0.3 \mathrm{~V}$ and $-1.3 \mathrm{~V}$ vs. $\mathrm{Ag} / \mathrm{AgCl}$. No current was observed until the potential reaches values higher than $-1.3 \mathrm{~V}$, then, the cathodic current begins to increase rapidly, which is associated with hydrogen reduction according to ${ }^{7}$ :

$$
2 \mathrm{H}_{2} \mathrm{O}+2 e^{-} \rightarrow \mathrm{H}_{2}+2 \mathrm{OH}^{-}
$$

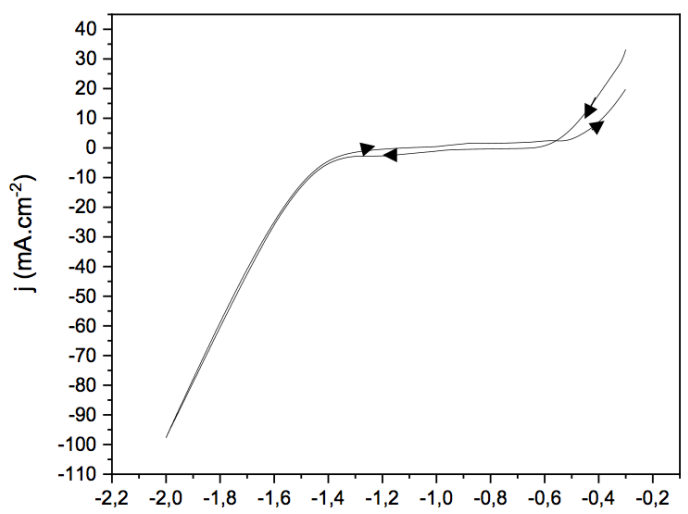

Figure 1. Cyclic voltammogram on a Fe substrate in $\mathrm{KCl}$ solution at $\mathrm{pH}=4.5$ (electrolyte 1 ), scan rate $=25 \mathrm{mV} / \mathrm{s}$.

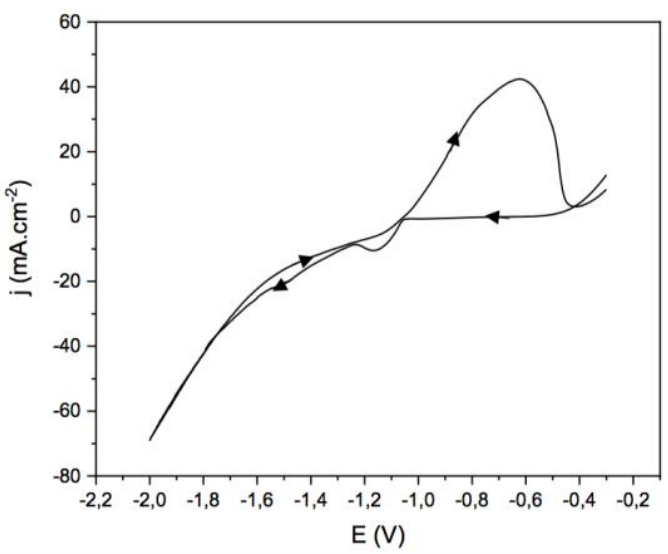

Figure 3. Cyclic voltammogram of mild steel in an electrolytic bath containing $\mathrm{Zn}(\mathrm{II})$, scan rate $=25 \mathrm{mV} / \mathrm{s}$.
The voltammogram realized in a solution containing $\mathrm{KCl}+\mathrm{H}_{3} \mathrm{BO}_{3}$ (Fig.2) has the same shape as in electrolyte 1 . Boric acid is considered a very weak acid, with a tabulated ionization constant around $\mathrm{pK}_{\mathrm{a}}=9.2^{8}$. Yet, in the presence of a strong base like $\mathrm{NaOH}(\mathrm{pKa}=14.8)$, a reaction takes place according to the following equation:

$\mathrm{H}_{3} \mathrm{BO}_{3}+\mathrm{NaOH} \rightarrow \mathrm{H}_{2} \mathrm{BO}_{3}{ }^{-}+\mathrm{Na}^{+}+\mathrm{H}_{2} \mathrm{O}$

Therefore, boric acid does not have any effect on the hydrogen evolution reaction.

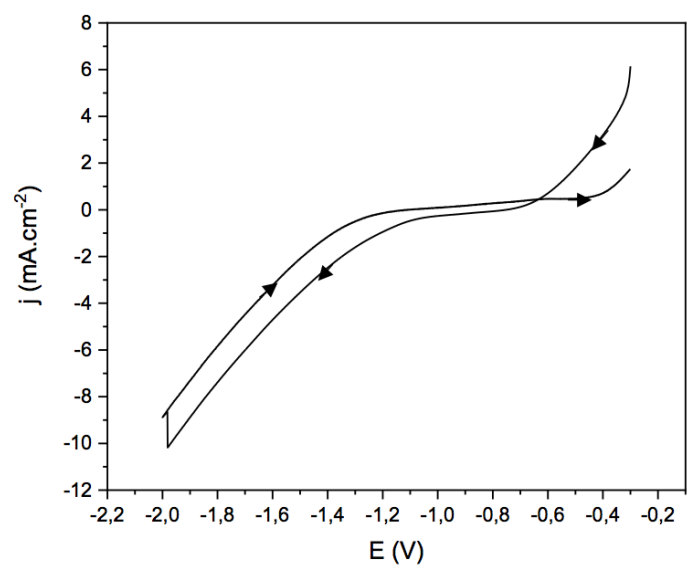

Figure 2. Cyclic voltammogram of a Fe substrate in $\mathrm{KCl}+\mathrm{H}_{3} \mathrm{BO}_{3}$ solution at $\mathrm{pH}=4.5$ (electrolyte 2 ), scan rate $=25 \mathrm{mV} / \mathrm{s}$.

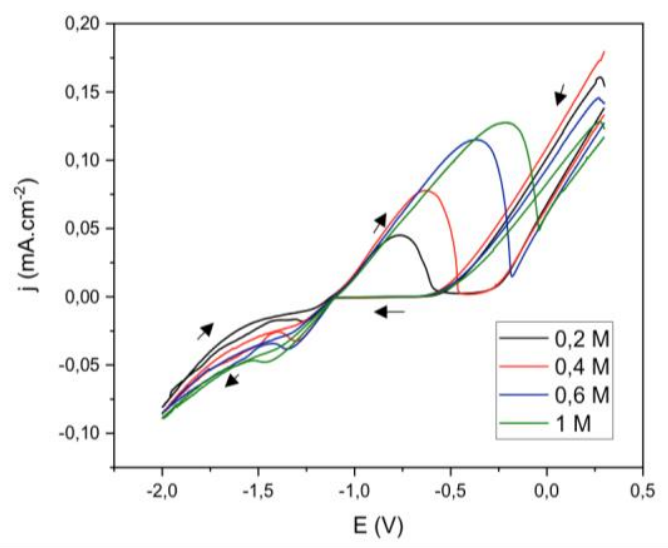

Figure 4. Cyclic voltammograms performed on mild steel from an electrolytic bath containing different $\mathrm{Zn}$ concentrations 
In Fig.3, the cathodic current increases sharply at $-1.05 \mathrm{~V}$ vs. $\mathrm{Ag} / \mathrm{AgCl}$ and gives rise to a cathodic peak at around $-1.17 \mathrm{~V}$ vs. $\mathrm{Ag} / \mathrm{AgCl}$. This peak is related to $\mathrm{Zn}^{2+}$ reduction during the cathodic scan according to the following reactions ${ }^{9}$ :

$\mathrm{Zn}^{2+} \rightarrow \mathrm{Zn}^{2+}$ ads

$\mathrm{Zn}^{2+}$ ads $+e^{-} \rightarrow \mathrm{Zn}^{+}$ads

$\mathrm{Zn}^{+}{ }_{\text {ads }}+e^{-} \rightarrow \mathrm{Zn}$

At about $-1.55 \mathrm{~V}$, we perceive an inflexion point; it is probably due to the formation of zinc in preference to hydrogen. In fact, with increasing current density. Zinc displaces hydrogen already on the surface, preventing the thermodynamically favored hydrogen reaction ${ }^{9}$.

When the potential scan is reversed, a hysteresis appears. Probably this is a crossover potential at which nucleation and growth take place ${ }^{1-10}$. During the reverse anodic scan, an oxidation peak appears, at $-0.6 \mathrm{~V}$, which represents the anodic dissolution of the previously deposited zinc metal.

\section{Effect of $\mathrm{Zn}$ concentration}

\section{Voltammetric study}

The effect of $\mathrm{Zn}$ concentration, in the range 0.2 to $1 \mathrm{M}$, on the cyclic voltammograms is shown in Fig.4. Cyclic voltammograms of $\mathrm{Zn}$ reduction show that increasing the $\mathrm{Zn}$ concentration causes a gradual increase in cathodic current. Additionally, as the $\mathrm{Zn}$ concentration is increased, the area covered by the anodic curve is increased, indicating that much more zinc is deposited. This can be connected with the increase in $\mathrm{Zn}$ deposition efficiency during the cathodic process with an increase in solution $\mathrm{Zn}$ concentration ${ }^{11}$.

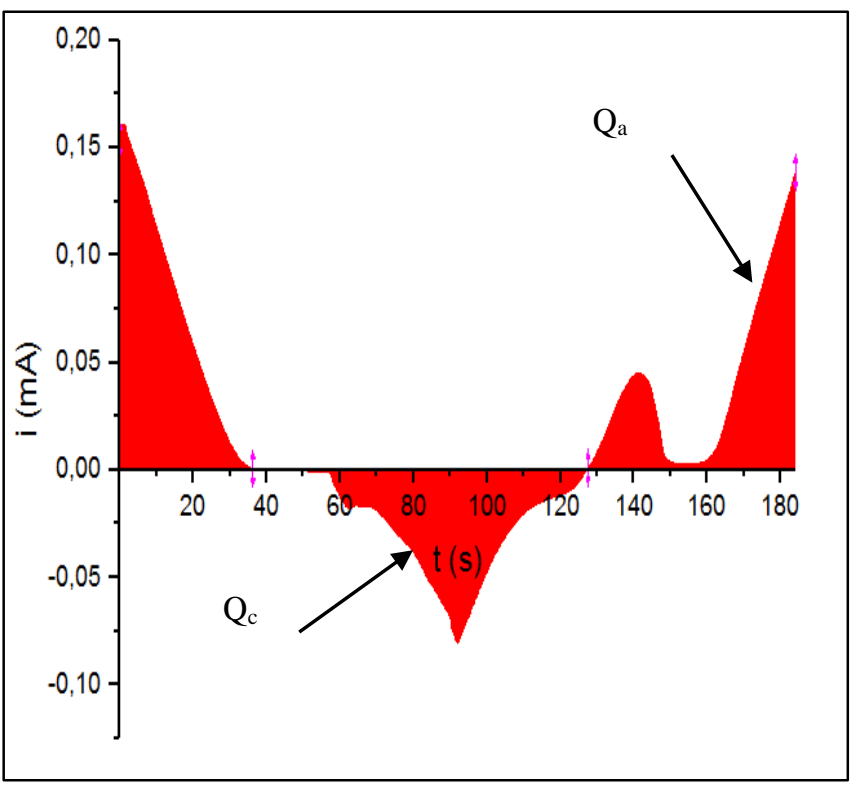

Figure 5. The voltammogram $\mathrm{i}=\mathrm{f}(\mathrm{E})$ converted into $\mathrm{i}=\mathrm{f}(\mathrm{t})$

\section{Electric charge}

The effect of $\mathrm{Zn}$ concentration on the electric charge has been studied. To calculate the cathodic charge $\mathrm{Q}_{\mathrm{c}}$, related to $\mathrm{Zn}$ deposition and the anodic charge $\mathrm{Q}_{\mathrm{a}}$, related to $\mathrm{Zn}$ dissolution, we have integrated the areas of reduction and oxidation peaks of $\mathrm{Zn}$ voltammograms (Fig. 5). The evolution of the cathodic and anodic charges as a function of $\mathrm{Zn}$ concentration is shown in Fig. 6.

We note that $\mathrm{Q}_{\mathrm{c}}$ decreases while $\mathrm{Q}_{\mathrm{a}}$ increases with increasing $\mathrm{Zn}$ concentration. The improvement in $\mathrm{Q}_{\mathrm{a}}$ variation can be attributed to the enhancement of the kinetic of $\mathrm{Zn}$ deposition with increasing $\mathrm{Zn}$ concentration as well as the metal oxidation, while the weaker value of $\mathrm{Q}_{\mathrm{c}}$ indicates that the discharge of $\mathrm{H}^{+}$ protons becomes more difficult with increasing the $\mathrm{Zn}$ concentration $^{12,13}$.

\section{Current efficiency}

The current efficiency of $\mathrm{Zn}$ deposition is calculated owing to the ratio of the charge of dissolution $\mathrm{Q}_{\mathrm{a}}$ to the charge of deposition $\mathrm{Q}_{\mathrm{c}}$ during $\mathrm{Zn}$ electrodeposition with different $\mathrm{Zn}$ concentrations. The current efficiency $\mathrm{CE}$ is calculated according to the following equation ${ }^{9}$ :

$$
C E(\%)=\frac{Q_{a}}{Q_{c}} \times 100
$$

One notices that for a $\mathrm{Zn}$ concentration more than $0.4 \mathrm{M}$, the current efficiency exceeds $100 \%$, it is probably due to the formation of a film of zincate as a result of zinc dissolution, i.e. a dissolution/precipitation process occurs, according to ${ }^{14}$ : 


$\mathrm{Zn}(\mathrm{SO})_{4}+2 \mathrm{NaOH} \rightarrow \mathrm{Zn}(\mathrm{OH})_{2}+\mathrm{Na}_{2} \mathrm{SO}_{4}$
$\mathrm{Zn}(\mathrm{OH})_{2}+2 \mathrm{NaOH} \rightarrow \mathrm{Na}_{2} \mathrm{ZnO}_{2}+2 \mathrm{H}_{2} \mathrm{O}$
$----------------------\mathrm{NaO}_{2}+\mathrm{Na}_{2} \mathrm{SO}_{4}+2 \mathrm{H}_{2} \mathrm{O}$

The dissolution of the oxidation product $\left.\left(\operatorname{as} \mathrm{Zn}(\mathrm{OH})_{2}\right)^{-}\right)$is characterized by the ratio, $\frac{Q_{a}}{Q_{c}}$ of the charges under the anodic, and corresponding cathodic peak. When a dissolution process accompanies metal

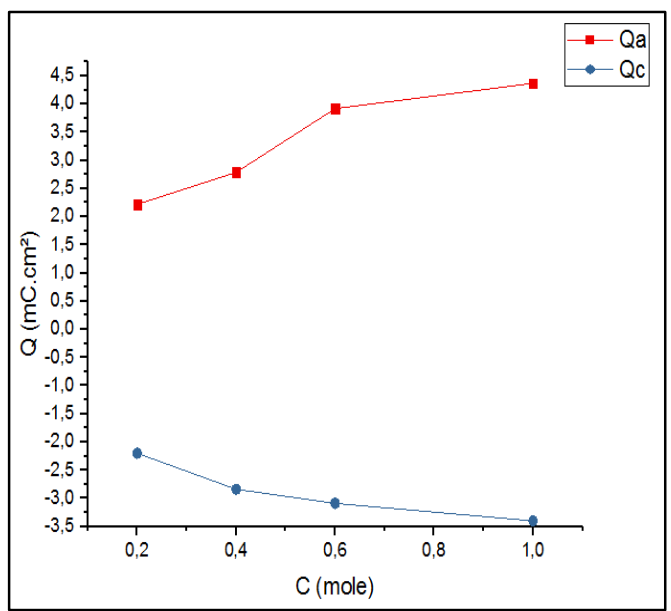

Figure 6. The evolution of $\mathrm{Q}_{c}$ and $\mathrm{Q}_{\mathrm{a}}$ as a function of $\mathrm{Zn}$ concentration

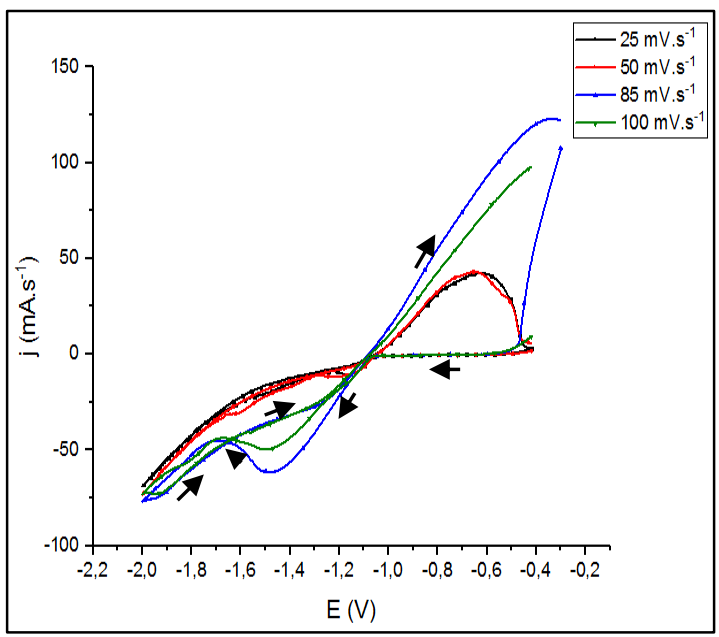

Figure 8. The voltammograms of $\mathrm{Zn}$ deposition/dissolution on mild steel at various scan rates

\section{Effect of scan rate}

\section{Voltammetric study}

Fig.8 shows the voltammograms of $\mathrm{Zn}$ deposition on mild steel at various scan rates. The anodic peak potentials became more positive with the scan rate while the cathodic peak potentials became more negative, indicating that reduction becomes more difficult and the system is irreversible ${ }^{15}$. oxidation with oxide film formation, the anodic/cathodic charge ratio $\frac{Q_{a}}{Q_{c}}$ is usually $>1$ and mass-transport dependent ${ }^{13}$ (Fig.7).

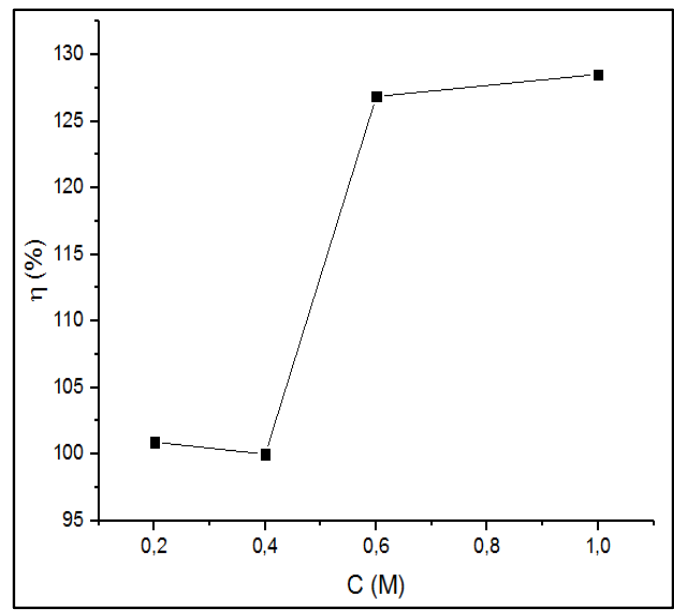

Figure 7. Current efficiency variation as a function of $\mathrm{Zn}$ concentration

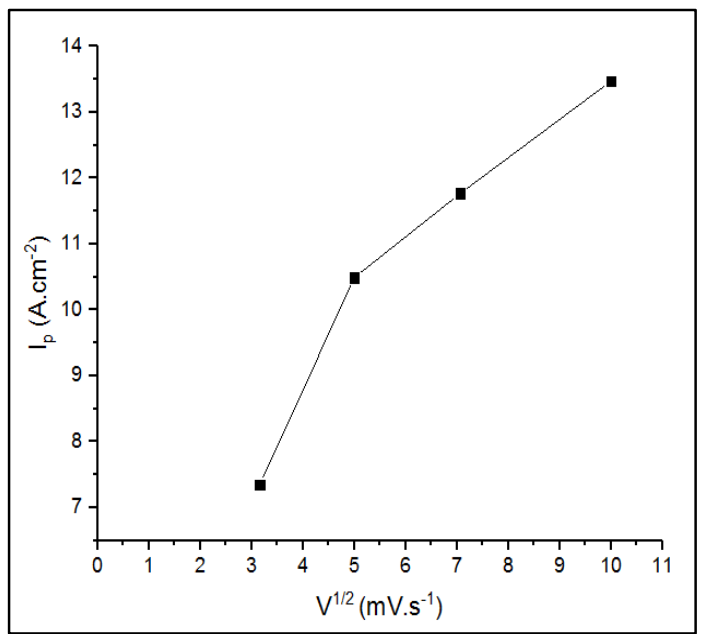

Figure 9. The evolution of the intensity of the peak $I_{p}$ as a function of the square root of the scan rate $v^{1}$

The study of the evolution of the intensity of the peak $I_{p}$ as a function of the square root of the scan rate $v^{1 / 2}$ can inform us about the nature of the limiting step in an electrochemical process. The peak current density, for an irreversible voltammogram, is given by the following equation ${ }^{16}$ :

$I_{p}=0.4958 \frac{(n F)^{3 / 2} \propto^{1 / 2}}{(R T)^{1 / 2}} S D^{1 / 2} v^{1 / 2} C^{\text {sol }}$ 
Where: $\mathrm{n}$ : the valency number of ions of the substance, F $\left(\mathrm{C} \cdot \mathrm{mol}^{-1}\right)$ : the Faraday constant (96500), $\alpha$ : the anodic charge transfer coefficient $(0<\alpha<1)$, R $\left(\mathrm{J} \cdot \mathrm{mol}^{-1} \cdot \mathrm{K}^{-1}\right)$ : the gas constant $(8.314462), \mathrm{S}\left(\mathrm{cm}^{2}\right)$ : the electrode area, $\mathrm{D}\left(\mathrm{m}^{2} . \mathrm{s}^{-1}\right)$ : the diffusion coefficient of electro-active species and $C^{\text {sol }}\left(\mathrm{mol} . \mathrm{cm}^{-3}\right)$ : the concentration of electro-active species in the solution.

The plot (Fig.9) is a slight concavity curve facing scan rates; this means that the zinc reduction process is associated with charge transfer coupled with mass transfer.
The evolution of the potential of the peak Ep as a function of the natural logarithm of the scan rate $\ln \left(v_{b}\right)$ given by the following formula ${ }^{16}$, (where $k^{0}\left(\mathrm{~cm} . \mathrm{s}^{-1}\right)$ is a rate constant $)$ :

$$
E_{p}=E^{0 \prime}-\frac{R T}{\propto n F}\left[0.780+\ln \left(\frac{D^{1 / 2}}{k^{0}}\right)+\ln \left(\frac{\propto n F v}{R T}\right)^{1 / 2}\right]
$$

Allows the characterization of the reaction mechanism on the electrode. Since, $E_{p}=f\left(\ln \left(v_{b}\right)\right)$ is a line with a slope different from zero, thus the reaction to the electrode is slow (Fig.10) ${ }^{17}$.

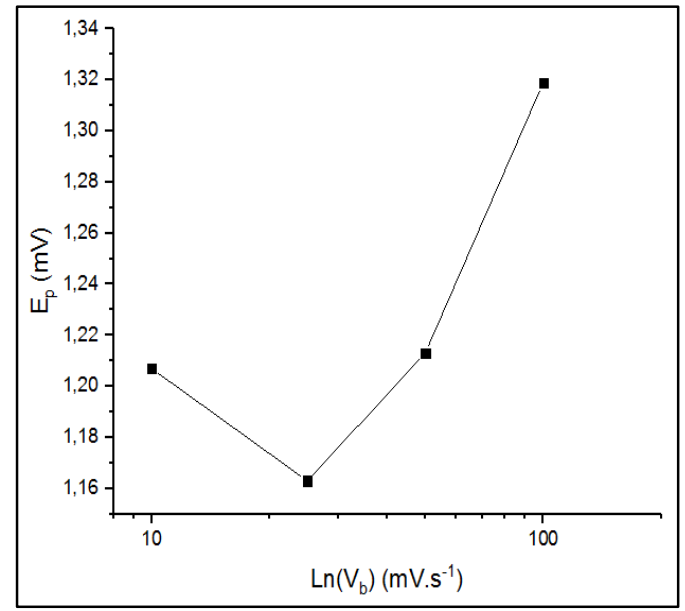

Figure 10. The evolution of the potential of the peak $E_{p}$ as a function of the natural logarithm of the scan rate $\ln \left(\mathrm{v}_{\mathrm{p}}\right)$

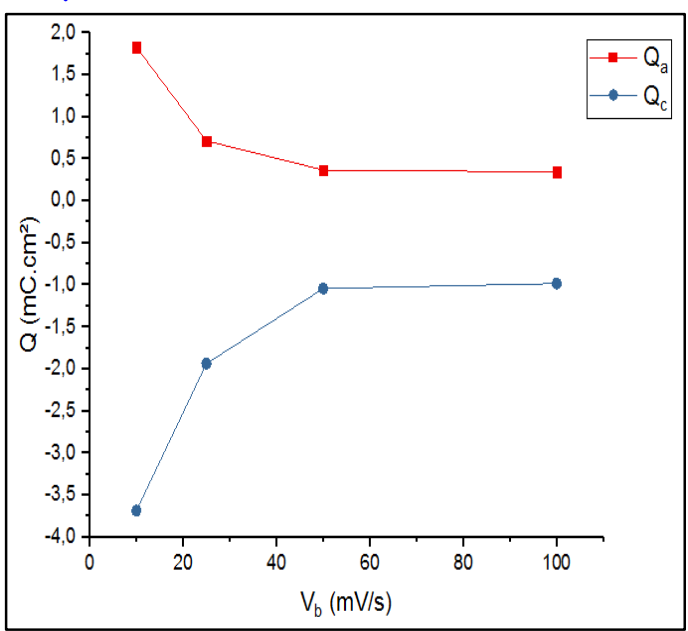

Figure 11. The evolution of $\mathrm{Q}_{\mathrm{c}}$ and $\mathrm{Q}_{\mathrm{a}}$ as a function of the scan rate

\section{Electric charge}

We note that Qc increases, with increasing the scan rate, showing that a big part of the cathodic charge is consumed in hydrogen evolution, while Qa decreases, which can be attributed to the decrease of the kinetic of $\mathrm{Zn}$ deposition, with the rise of the scan rate ${ }^{12}$ (Fig.11).

\section{Current efficiency}

In Fig.12, we can quantify the contribution of the hydrogen evolution during $\mathrm{Zn}$ electrodeposition with different scan rates. The current efficiency decreases

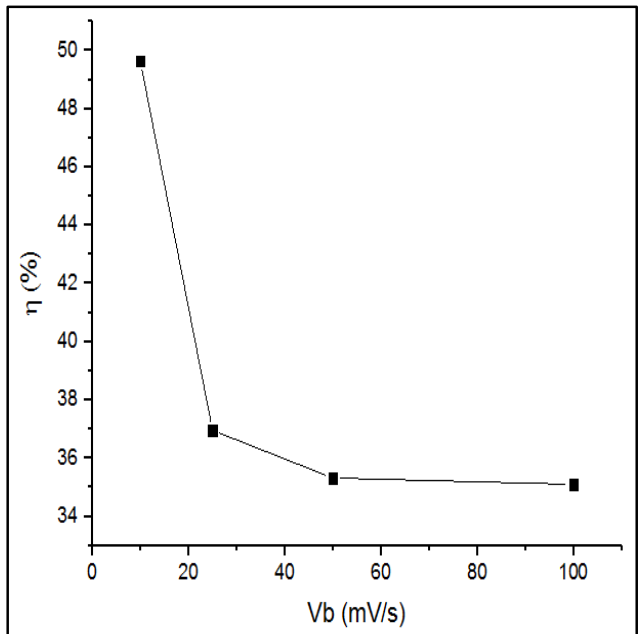

Figure 12. Current efficiency variation as a function of scan rate

gradually from $49.72 \%$ to $35.85 \%$ with increasing the scan rate from $10 \mathrm{mV} . \mathrm{s}^{-1}$ to $100 \mathrm{mV} . \mathrm{s}^{-1}$. Probably this is because at slow scan rates, $\mathrm{Zn}$ is correctly reduced on the surface, whereas, at faster scan rates, the species formed remain into the bulk electrolyte because they do not have enough time to be reduced 18

\section{Galvanostatic deposition}

Effect of current density in the plating bath on deposition potential, thickness, deposition rate and current efficiency 
Electrodeposition can be performed by controlling either the potential or current. In industrial coatings preparation, the current step method, also known as the galvanostatic method, is the most practical. The advantage of the galvanostatic method is that the thickness of the as-deposited layer can be easily controlled according to Faraday's law 5. Accordingly, the deposition of a $\mathrm{Zn}$ coating can be applied using different current densities. However, the applied current densities should be superior to the limiting current density of $\mathrm{Zn}$ deposition, which is $\approx$ $10 \mathrm{~mA} . \mathrm{cm}^{-2}$ as can be seen in $\mathrm{Zn}$ voltammogram exposed above (Fig. 3). Galvanostatic experiments were carried out in a range of current density varying from 16 to $40 \mathrm{~mA} \cdot \mathrm{cm}^{-2}$.

Fig. 13 presents the variation of the deposition potential (Ed) during $\mathrm{Zn}$ electrodeposition with different current densities. A further increase in current density leads to a notable shift of Ed towards more negative values. For instance, $\mathrm{Zn}$ deposition at $16 \mathrm{~mA} . \mathrm{cm}^{-2}, 24 \mathrm{~mA} . \mathrm{cm}^{-2}, 32 \mathrm{~mA} . \mathrm{cm}^{-2}$ and $40 \mathrm{~mA} . \mathrm{cm}^{-}$ ${ }^{2}$ exhibit an average deposition potential $\mathrm{E}_{\mathrm{d}}$ of $-1.42 \mathrm{~V}$, $-1.51 \mathrm{~V},-1.62 \mathrm{~V}$ and $-1.85 \mathrm{~V}$ respectively. Further increase of the current density leads to stronger potential oscillations in the curves due to intensive hydrogen evolution ${ }^{19,20}$.

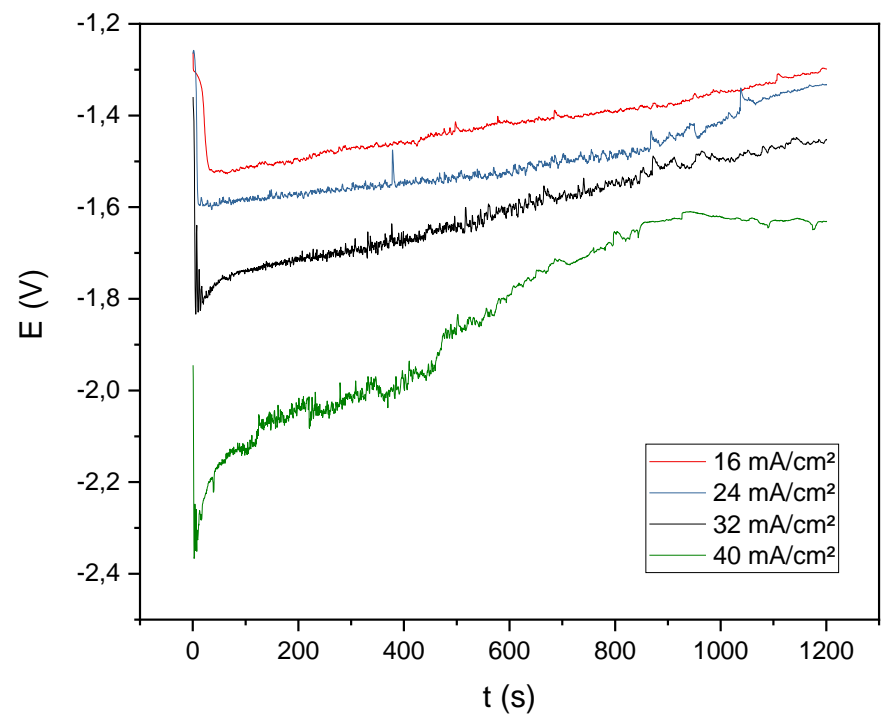

Figure 13. The evolution of the deposition potential $E_{d}$ during $\mathrm{Zn}$ electrodeposition with different current densities

The effect of current density on the thickness(e), which is given by the following relation:

$e=\frac{\Delta m}{\rho S}$

Where $\Delta \mathrm{m}(\mathrm{g})$ : the deposited mass of coating; $\rho\left(\mathrm{g} . \mathrm{cm}^{-3}\right)$ : the density of coating and $\mathrm{S}\left(\mathrm{cm}^{2}\right)$ : the surface area of the substrate, is shown in Table 2. It can be seen that the thickness increases with increasing current density, as well as the deposition rate $v\left(\mu \mathrm{m} \cdot \mathrm{h}^{-1}\right)$, which is calculated according to the following equation:

$v=\frac{m_{2}-m_{1}}{\rho S t}$

Where $\mathrm{m}_{2}(\mathrm{~g})$ : mass of the sample after the deposition, $\mathrm{m}_{1}(\mathrm{~g})$ : mass of the sample before the deposition and $\mathrm{t}(\mathrm{s})$ : deposition time.

Table 2. Effect of current density on thickness, deposition rate and current efficiency

\begin{tabular}{|l|l|l|l|}
\hline $\begin{array}{l}\text { Current density }(\mathrm{j}) \\
\mathrm{mA} \cdot \mathrm{cm}^{-2}\end{array}$ & $\begin{array}{l}\text { Thickness (e) } \\
\mu \mathrm{m}\end{array}$ & $\begin{array}{l}\text { Deposition rate }(\mathrm{v}) \\
\mu \mathrm{m}^{-1}\end{array}$ & $\begin{array}{l}\text { Current Efficiency }(\mathrm{CE}) \\
\%\end{array}$ \\
\hline 16 & 5.7 & 17.1 & 63 \\
\hline 24 & 6.4 & 19.2 & 47 \\
\hline 32 & 8.8 & 26.4 & 46.56 \\
\hline 40 & 11.7 & 35.1 & 52.5 \\
\hline
\end{tabular}

Moreover, it is observed (Table 2) that the current efficiency (CE) decreases with increasing current density that could be attributed to the rapid increase in hydrogen evolution. The $\mathrm{CE}$ is obtained using the equation:

$$
C E=\frac{\Delta m}{m_{t h}} * 100
$$

$m_{t h}$ is calculated by the mean of Faraday's law:

$m_{t h}=\frac{j t M}{n F}$

Where $\mathrm{j}\left(\mathrm{mA} \cdot \mathrm{cm}^{-2}\right)$ : the applied current density and $\mathrm{M}\left(\mathrm{g} \cdot \mathrm{mol}^{-1}\right)$ : molar mass of the substance. 
Since in electrodeposition processes hydrogen is the second element produced at the cathode, many works had investigated the influence of hydrogen evolution on the reaction of zinc deposition ${ }^{19-22}$ and depending on the composition of the electrolyte and plating conditions; the current efficiency may vary over a broad range. For the evaluation of the impact of hydrogen evolution reaction (HER) on the current efficiency, Dundlker et al. ${ }^{23}$ have approximated the current efficiency $(\mathrm{CE})$ by the ratio of the zinc reaction current density to the total electrode current density by the following equation:

$C E \approx \eta_{j}=\frac{j_{Z n}}{j}$

Where $j_{Z n}$ is the current density of zinc reaction and $j$ is the total electrode current density. Considering:

$j=j_{Z n}+j_{H_{2}}$

Where $j_{H_{2}}$ is the current density of hydrogen reaction. Fig. 14 shows the variation of the polarization of $\mathrm{Zn}$ electrode, in case of considering the effect of HER $\left(j_{x} ; x=\mathrm{Zn}\right.$ or $\left.H_{2}\right)$ and in case of
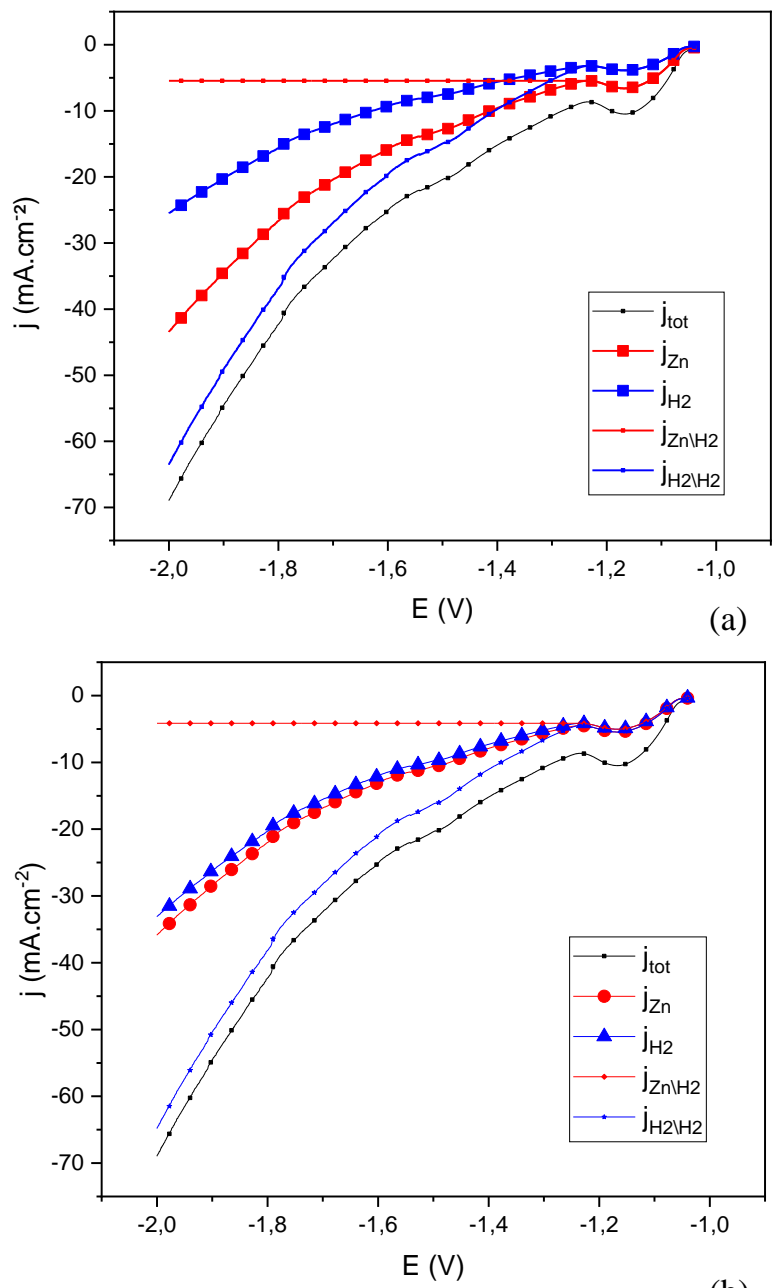

(b)

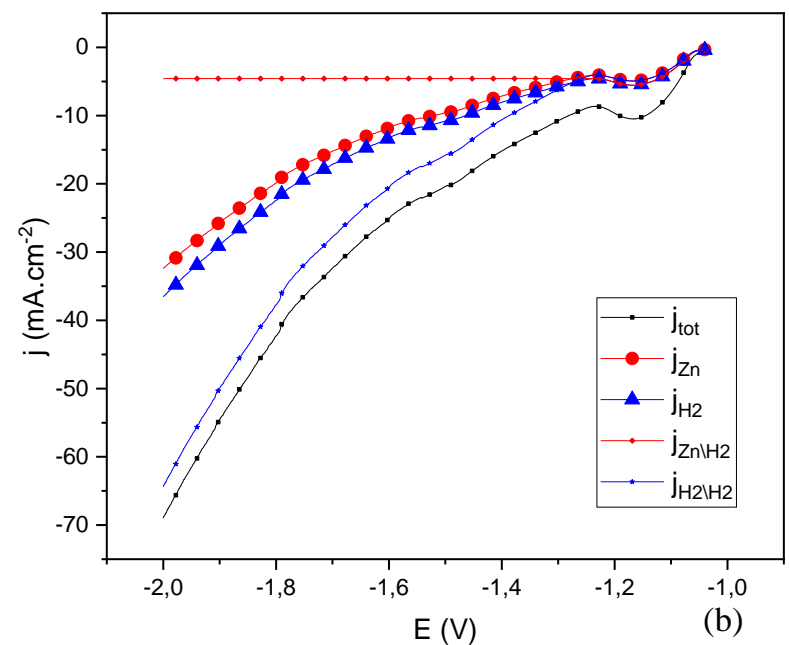

neglecting its effect $\left(j_{x \backslash H_{2}}\right)$, with different current densities.

By neglecting HER effect, we note that zinc reaction is under mass transfer limitation, which is exhibited by the presence of the plateau of the zinc limiting current density. Nevertheless, taking in consideration the HER effect on the zinc reaction, we distinguish a significant run of the HER near the mass transfer limitation of the zinc deposition, indicating the improvement of the mass transfer rate of the zincate ions with hydrogen evolution ${ }^{23}$.

Fig. 15 shows the variation of the $\mathrm{CE}$ as a function of current density. The drop in the CE with increasing the current density is attributed to the HER. However, with higher current densities, the displacement of hydrogen ions by zinc leads to an increase of current efficiency. The rising hydrogen bubbles may cause extra convection within a diffusion layer, leading to enhanced mass transport of zincate ions to an electrode surface, which partially compensates the drop of the current efficiency of the zinc deposition at higher current flows ${ }^{23}$.

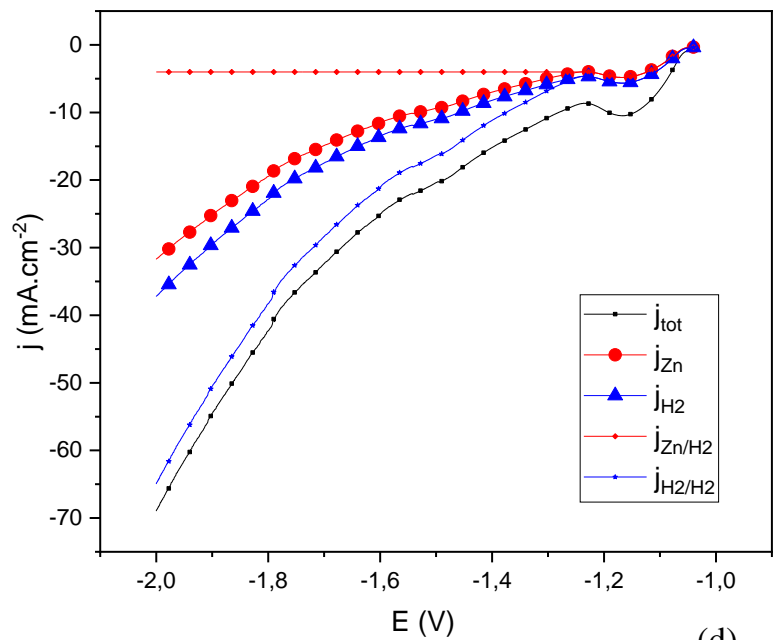

(d)

Figure 14. The variation of the polarization of $\mathrm{Zn}$ electrode, in case of considering the effect of HER $\left(\mathrm{j}_{\mathrm{x}} ; \mathrm{x}=\mathrm{Zn}\right.$ or $\left.\mathrm{H}_{2}\right)$ and in case of neglecting its effect $\left(\mathrm{j}_{\mathrm{x} \backslash \mathrm{H}_{2}}\right)$, with different current densities: (a) $16 \mathrm{~mA} . \mathrm{cm}^{-2}$, (b) $24 \mathrm{~mA} \cdot \mathrm{cm}^{-2}$, (c) $32 \mathrm{~mA} \cdot \mathrm{cm}^{-2}$ and (d) $40 \mathrm{~mA} \cdot \mathrm{cm}^{-2}$ 


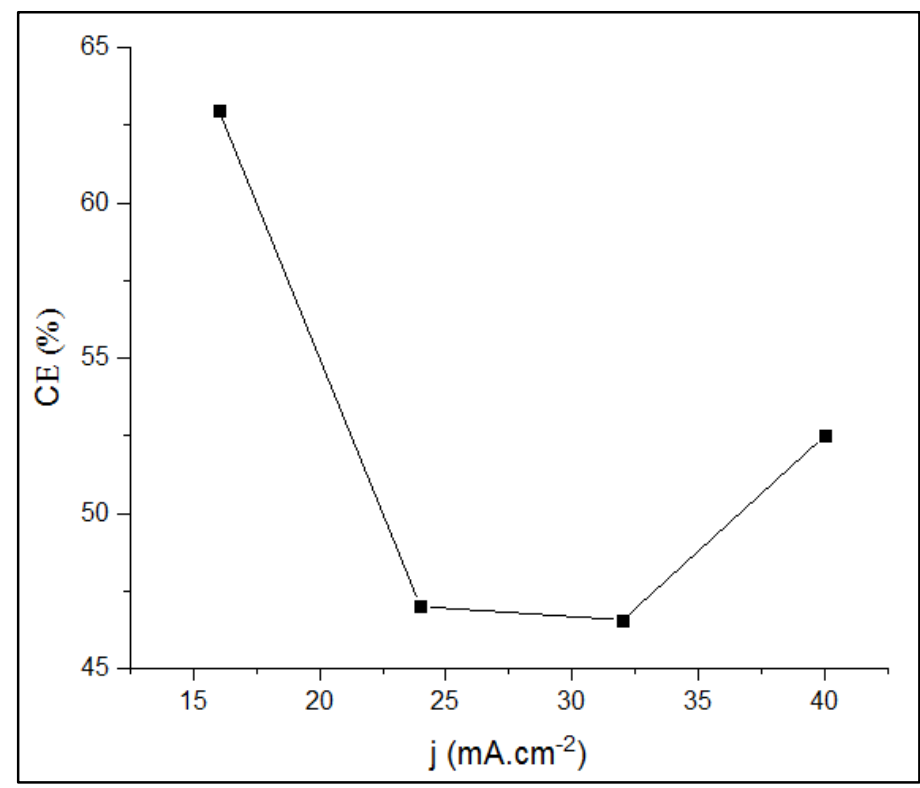

Figure 15. The variation of the $\mathrm{CE}$ as a function of current density

Effect of the applied current density on the morphology and crystallographic structure of Zn coating
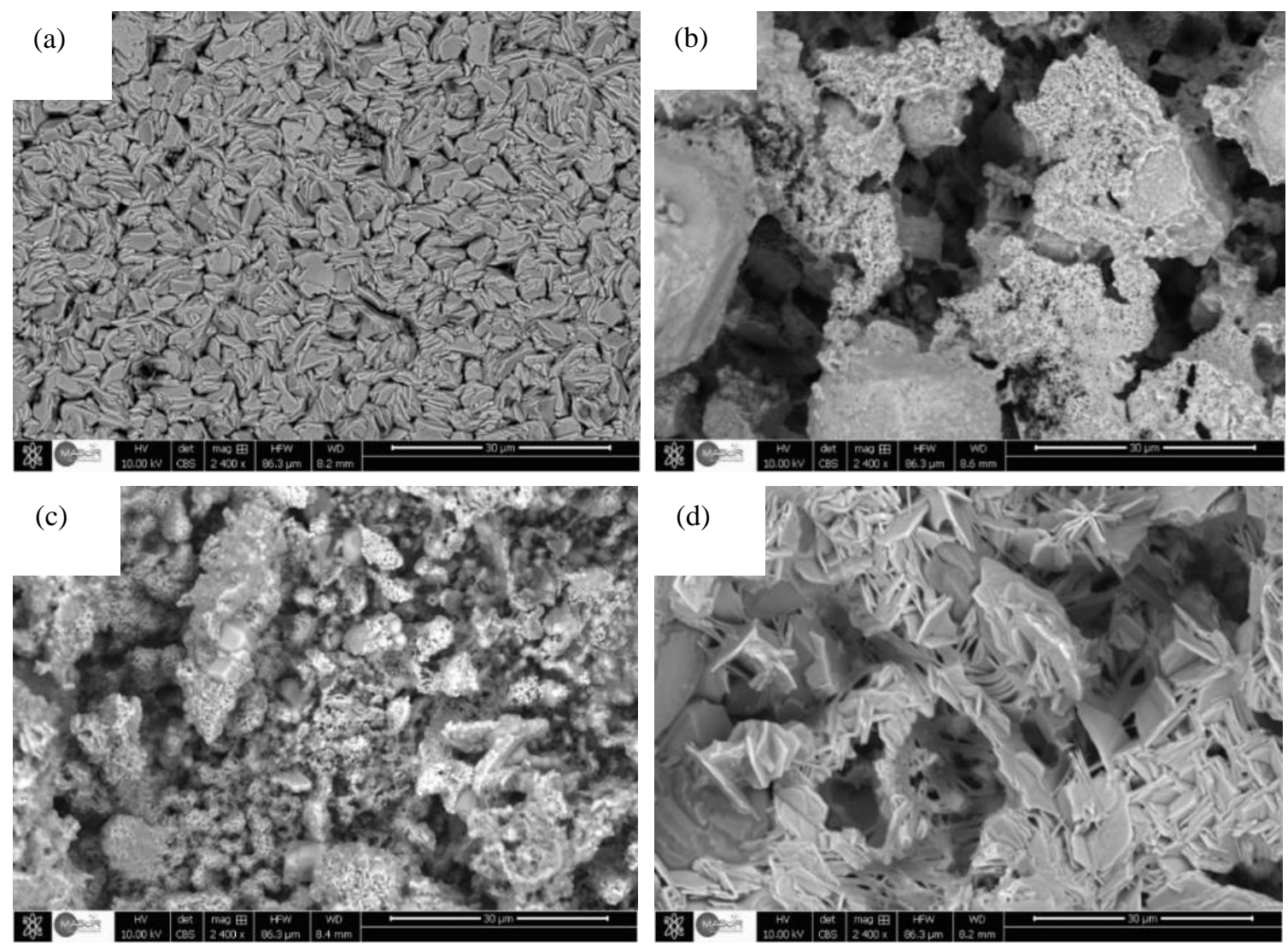

Figure 16. SEM images of Zn deposit obtained with different current densities: (a) $16 \mathrm{~mA} . \mathrm{cm}^{-2}$, (b) $24 \mathrm{~mA} . \mathrm{cm}^{-2}$, (c) $32 \mathrm{~mA} . \mathrm{cm}^{-2}$ and (d) $40 \mathrm{~mA} \cdot \mathrm{cm}^{-2}$

\section{Morphological characterization}

SEM images of investigated $\mathrm{Zn}$ coatings are presented in Fig. 16a-d. At a low current density (Fig. 16a), a platelet morphology is observed; the grains have typical hexagonal close-packed crystals, which is a typical morphology of $\mathrm{Zn}$ deposits in the absence of additives. The deposit is compact, showing a homogeneous structure which affords a smooth and 
brilliant aspect. With increasing the current density (Fig. 16b-c), coarse grains, porous and blackish grey deposits are obtained. With higher current density (40 $\mathrm{mA} . \mathrm{cm}^{-2}$ ) a flower-like shape is observed (Fig. 16d), with a transient from bidimensional to the tridimensional structure. However, the heterogeneous structure and the random growing of the nano-grains provides a dull and rough deposit 2, 11, 17, 24-28. This result is by those reported by N. Alias et al. ${ }^{29}$, who explained that the change in morphology of $\mathrm{Zn}$ deposit from dense and uniaxial to disperse and dendritic was due to the increase in current density used for the deposition.

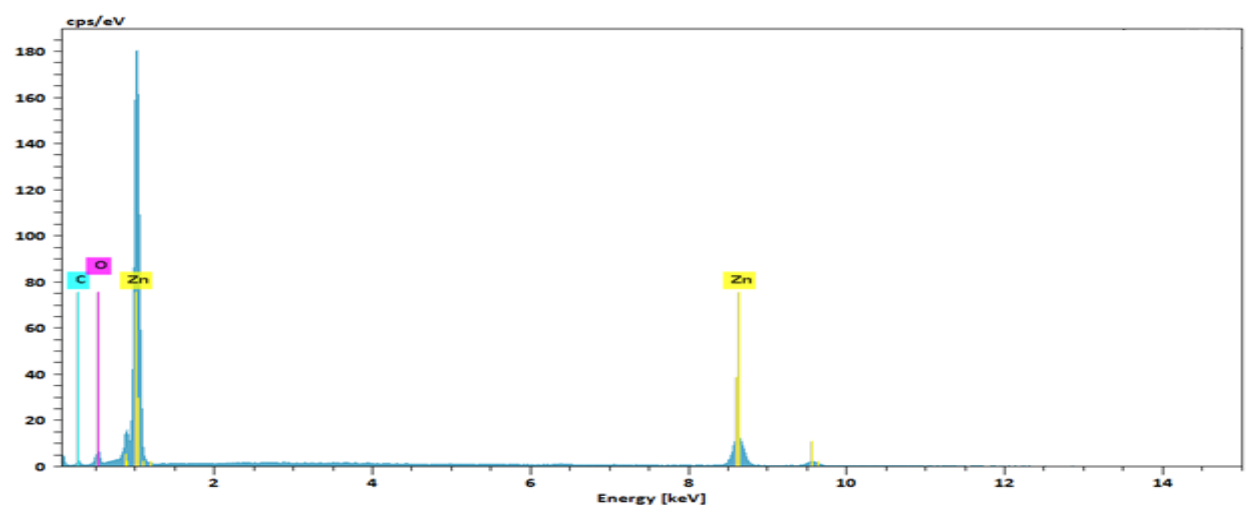

(a)

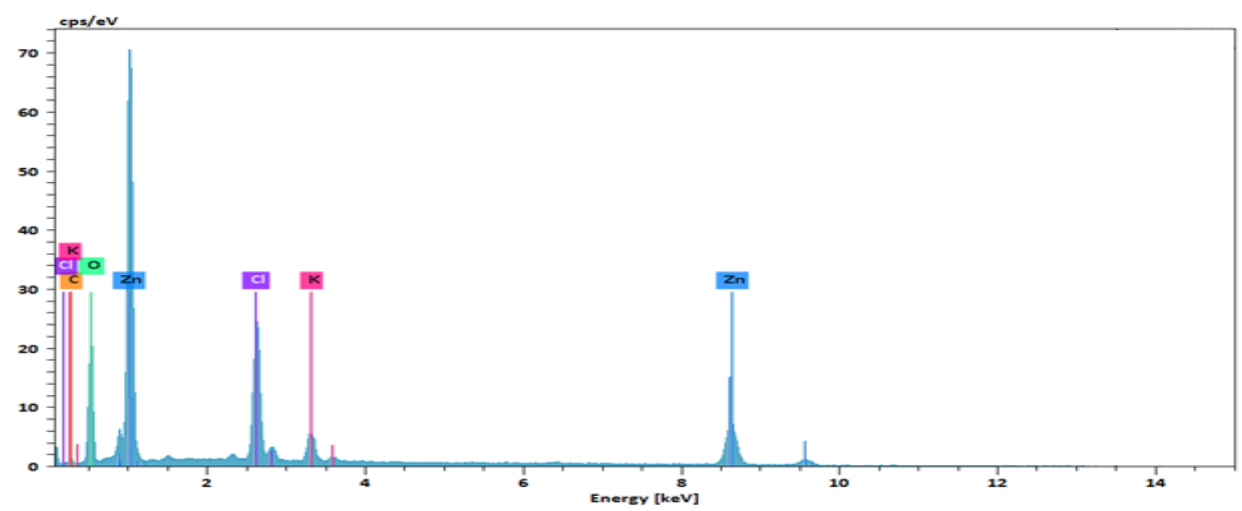

(b)

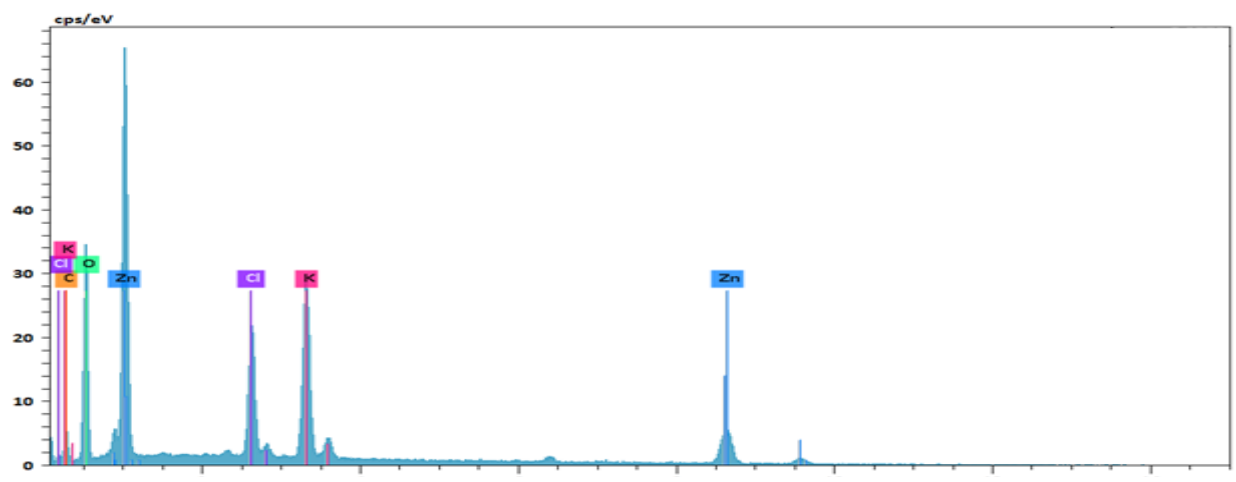

(c)

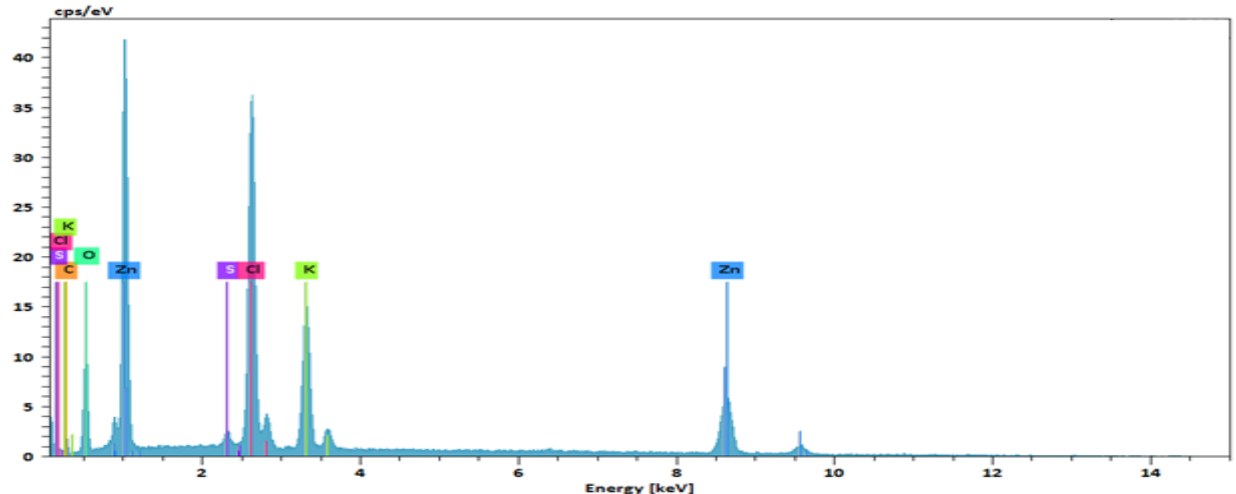

(d)

Figure 17. EDS analysis of the Zn coating obtained with different current densities: (a) $16 \mathrm{~mA} . \mathrm{cm}^{-2}$, (b) $24 \mathrm{~mA} \cdot \mathrm{cm}^{-2}$, (c) $32 \mathrm{~mA} \cdot \mathrm{cm}^{-2}$ and (d) $40 \mathrm{~mA} \cdot \mathrm{cm}^{-2}$ 


\section{Compositional analysis (EDS)}

The EDS analysis shows the elemental composition of $\mathrm{Zn}$ deposit on a steel substrate. The spectrum for a deposition at low current density shows a prominent peak of $\mathrm{Zn}$, and noteworthy peaks of $\mathrm{O}$ and C (Fig. 17a). The element of carbon mainly comes from the steel substrate, while the oxygen should result from some oxides on the top surface. When we increase the current density, new peaks of $\mathrm{K}, \mathrm{Cl}$ and even $\mathrm{S}$ appeared (Fig. 17b-c-d) ${ }^{30-32}$. Indeed, the rising hydrogen bubbles may cause extra convection within a diffusion layer, inducing $\mathrm{K}, \mathrm{Cl}$ and $\mathrm{S}$ transport and adsorption on the deposit. Rogers et al. ${ }^{33}$ reported that incorporation of sulfur increases with decreasing current density which is in disagreement with our results. Nitin et al. ${ }^{34}$ suggest that sulfur (S) and carbon (C) adsorb the crystallographic surface before being incorporated in the coating.

The results of the chemical composition of the obtained coatings are presented in Table. 3. They exhibit the average value computed using four measurements.

Table 3. Chemical composition of the obtained deposit at different current densities.

\begin{tabular}{|l|l|l|l|l|l|l|}
\hline $\begin{array}{l}\text { Current density } \\
\text { mA.cm }\end{array}$ & $\begin{array}{l}\text { C } \\
\text { \% }\end{array}$ & $\begin{array}{l}\mathbf{O} \\
\text { \% }\end{array}$ & $\begin{array}{l}\text { S } \\
\text { \% }\end{array}$ & $\begin{array}{l}\text { Cl } \\
\text { \% }\end{array}$ & $\begin{array}{l}\text { K } \\
\text { \% }\end{array}$ & $\begin{array}{l}\text { Zn } \\
\text { \% }\end{array}$ \\
\hline $\mathbf{1 6}$ & 15.81 & 11.26 & - & - & - & 72.92 \\
\hline $\mathbf{2 4}$ & 8.55 & 38 & - & 14.1 & 3.25 & 35.6 \\
\hline $\mathbf{3 2}$ & 9.02 & 34.03 & 1.02 & 7.31 & 11.66 & 36.95 \\
\hline $\mathbf{4 0}$ & 6.50 & 15.42 & 7.52 & 21.88 & 24.35 & 24.31 \\
\hline
\end{tabular}

\section{Conclusion}

In the present study, $\mathrm{Zn}$ coatings were produced by electrodeposition technique from a simple free additives bath on mild steel. The effect of the current density on the deposition potential, the thickness of the deposit, deposition rate and current efficiency was investigated, as well as the composition and the morphology of the elaborated deposits. The outcome of the results can be summarized as follows:

- $\mathrm{Zn}$ reduction is a slow reaction, which becomes more difficult with increasing the scan rate, because of HER, and is associated with charge transfer coupled with the mass transfer (diffusion).

- An increase in $\mathrm{Zn}$ concentration leads to an improvement in $\mathrm{Zn}$ deposition efficiency.

- A further increase in current density leads to a notable shift of Ed towards more negative values and an intensive hydrogen evolution.

- The thickness increases with increasing current density, while the current efficiency decreases. However, with higher current density, HER partially compensates the drop of the current efficiency, producing an enhancement in its value.

- The change in morphology of $\mathrm{Zn}$ deposit from dense and uniaxial to disperse and dendritic was due to the increase in current density.

- The EDX analyses revealed the presence of $\mathrm{Zn}$ and $\mathrm{O}$.

- An optimum $\mathrm{Zn}$ electrodeposition is achieved using $0.4 \mathrm{M} \mathrm{ZnSO}_{4}, 0.4 \mathrm{M} \mathrm{H}_{3} \mathrm{BO}_{3}, 1.25 \mathrm{M} \mathrm{KCl}$ and applying a current density of $16 \mathrm{~mA} \cdot \mathrm{cm}^{-2}$ for $20 \mathrm{~min}$.

\section{References}

1- Ö. Rasim, H.K. Ismail and K. Orhan, A Study on the Electrodeposited Cu-Zn Alloy Thin Films. Metallurgical and materials transactions a, 2016, 47A, 5609-5617.

2- Y. Yang, S. Liu, X. Yu, C. Huang, S. Chen, G. Chen and Q.H. Wu, Effect of additive on zinc electrodeposition in acidic bath, Surface Engineering, 2014, 000, 1-6.

3- K.R. Sriraman, S. Brahimi, J.A. Szpunar, J.H. Osborne and S. Yue: Characterization of corrosion resistance of electrodeposited $\mathrm{Zn}-\mathrm{Ni}$ $\mathrm{Zn}$ and Cd coatings, Electrochimica Acta, 2013, 105, 314-323.

4- D.K. Sahoo, H. Singh and N. Krishnamurthy, Electrochemical deposition of La-Mg alloys in $\mathrm{LaCl}_{3}-\mathrm{MgCl}_{2}-\mathrm{KCl}$ system with molten salt electrolysis process, J. Min. Metall. Sect. B-Metall. 2014, 50 (2) B, 109-114.

5- N. Loukil and M. Feki, Electrodeposition of Zn-Mn alloy coatings deposited from acidic chloride baths, Effect of deposition conditions on the $\mathrm{Zn}-\mathrm{Mn}$ electroplating, morphological and structural characterization, Applied Surface Science, Applied Surface Science, 2017, 410, 574-584, doi: 10.1016/j.apsusc.2017.02.075.

6- D. Sylla, J. Creus, C. Savall, O. Roggy, M. Gadouleau, Ph. Refait, Electrodeposition of Zn$\mathrm{Mn}$ alloys on steel from acidic $\mathrm{Zn}-\mathrm{Mn}$ chloride solutions, Thin Solid Films, 2003, 424, 171-178

7- R. Tena-Zaera, J. Elias, G. Wang, and C. LevyClement, Role of Chloride Ions on Electrochemical Deposition of $\mathrm{ZnO}$ Nanowire Arrays from O2 Reduction, J. Phys. Chem.C, 2007, 111, 16706- 16711.

8- M. Celeste C. Azevedo and Ana M.V. Cavaleiro, The Acid-Base Titration of a Very 
Weak Acid: Boric Acid, Journal of chemical education, 2012, 89, 767-770.

9- P.C. Foller, Improved slurry zinc/air systems as batteries for urban vehicle propulsion, Journal of applied electrochemistry, 1986, 16, 527-543.

10- N.N. Che Isa, Y. Mohd, M. H. Mohd Zaki and S.A. Syed Mohamad, Characterization of Copper Coating Electrodeposited on Stainless Steel Substrate, International Journal of Electrochemical Science, 2017, 12, 6010-6021, doi: 10.20964/2017.07.58.

11- A.E. Elsherie, Effects of cobalt, temperature and certain impurities upon cobalt electro-winning from sulfate solutions. Journal of Applied Electrochemistry, 2003, 33, 43-49.

12- E.C. Pereira, J.S. Santos, R. Matos and F. Trivinho-Strixino, Effect of temperature on co-electrodeposition in the presence of boric acid, Electrochimica Acta, 2007, 53, 644-649.

13- D. C. W. Kannangara and B. E. Conway, Zinc Oxidation and Redeposition Processesand Carbonate Solutions in Aqueous Alkali. J. Electrochem. Soc., Electrochemical Science and Technology, 1987, 134, $\mathrm{N}^{\circ} 4,894-905$.

14- A. P. Chatterjee, P. Mitra and A. K. Mukhopadhyay, chemically deposited zinc oxide thin film gas sensor, Journal of materials science, 1999, 34, 4225-4231

15- R. Sekar, S. Jayakrishnan and V. S. Muralidharan, Electrochemical behaviour of zinc acetate complexes: a cyclic voltammetry study, Transactions of the Institute of Metal Finishing, 2005, 83, 300-302.

16- Trémillon B., Electrochimie analytique et réactions en solution-Tome 2 Réactions et méthodes électrochimiques; ed. By Masson: Paris, 1993.

17- R.S. Nicholson and I. Shain, Single scan and cyclic methods applied to reversible, irreversible, and kinetic systems, Analytical Chemistry, 1964, 36, 706-723.

18- T. Boiadjieva, M. Monev, A. Tomandl, H. Kronberger, and G. Fafilek, Electrochemical studies on $\mathrm{Zn}$ deposition and dissolution in sulphate electrolyte, Journal of Solid State Electrochemistry, 2009, doi: 10.1007/s10008008-0594-3.

19- T. Casanova, F. Soto, M. Eyraud and J. Crousier, Hydrogen absorption during zinc plating on steel, Corrosion Science, 1997,39, 529-537.

20- Tz. Boiadjieva-Scherzer, H. Kronberger, G. Fafilek and M. Monev, Hydrogen evolution reaction on electrodeposited $\mathrm{Zn}-\mathrm{Cr}$ alloy coatings, Journal of Electroanalytical Chemistry, 2016. doi: 10.1016/j.jelechem.2016.10.059.

21- M. Monev, L. Mirkova, I. Krastev, Hr. Tsvetkova and St. Rashkov, Effect of brighteners on hydrogen evolution during zinc electroplating from zincate electrolytes, Journal of applied electrochemistry, 1998, 28, 1107-1112.

22- D. R. Gabe: The role of hydrogen in metal electrodeposition Processes. Journal of applied electrochemistry,

1997, 27, 908-915.

23- J. Dundálek, I. Šnajdr, O. Libánský, J. Vrána, J. Pocedič, P. Mazúr, and J. Kosek: Zinc electrodeposition from flowing alkaline zincate solutions, Role of hydrogen evolution reaction. Journal of Power Sources, 2017, 372, 221-226. doi: 10.1016/j.jpowsour.2017.10.077.

24- M. Froment and G. Maurin, Etude en microscopie électronique de la morphologie des dépôts électrolytiques de zinc,

Electrodeposition and Surface Treatment, 1975, 3, 245-260.

25- M. Kwon, D. Jo, S. H. Cho, H. T. Kim, J.-T. Park and J. M. Park: 'Characterization of the influence ofNi content on the corrosion resistance of electrodeposited $\mathrm{Zn}-\mathrm{Ni}$ alloy coatings'. Surface \& Coatings Technology, 2016, 288, 163-170. doi: 10.1016/j.surfcoat.2016.01.027.

26- K. Raeissi, A. Saatchi, M.A. Golozar and J.A. Szpunar: Effect of surface preparation on zinc electrodeposited texture, Surface \& Coatings Technology, 2005, 197, 229- 237. doi: 10.1016/j.surfcoat, 2004.09.024.

27- P.K. Leung, C. Ponce-de-Leon, C.T.J. Low, and F.C. Walsh: 'Zinc deposition and dissolution in methanesulfonic acid onto a carbon composite electrode as the negative electrode reactions in a hybrid redox flow battery'. Electrochimica Acta, 2011, 56, 6536- 6546. doi:10.1016/j.electacta.2011.04.111.

28- A. Gomes and M.I. da Silva Pereira, Pulsed electrodeposition of $\mathrm{Zn}$ in the presence of surfactants,.Electrochimica Acta, 2006, 51, 1342-1350. doi:10.1016/j.electacta.2005.06.023.

29- N. Alias and A. A. Mohamad, Morphology study of electrodeposited zinc from zinc sulfate solutions as anode for zinc-air and zinc-carbon batteries, Journal of King Saud University Engineering Sciences, 2015, 27, 43-48. doi: 10.1016/j.jksues.2013.03.003

30- A. Sharma, Y. J. Jang and J. P. Jung: 'Effect of current density on the morphology of electroplated tin'. Surface Engineering, 2015, 31, 458-464. doi: 10.1179/1743294414Y.0000000427.

31- K. Gang, L. Lingyan, L. Jintang, C. Chunshan and Z. Zheng: 'Study on lanthanum salt conversion coating modified with citric acid on hot dip galvanized steel'. Journal of rare earths, 2010, 28, 461-465. doi: 10.1016/S10020721(09)60134-4.

32- J. Zhang, C. Gu and J. Tu, Potentiodynamic deposition and corrosion behavior of thin $\mathrm{Zn}$ Sn coatings with layered structure and varied 
composition from deep eutectic solvent'. Surface \& Coatings Technology, 2016, doi: 10.1016/j.surfcoat.2016.10.004

33- G. T. Rogers 1, M. J. Ware and R. Y. Fellows, The Incorporation of Sulfur in Electrodeposited Nickel, Using Thiourea as a Brightener and Leveler, Journal of the electrochemical society, 1960, 107, 677-682.
34- N. P.Wasekar, P. Haridoss, S.K. Seshadri, and G. Sundararajan: 'Influence of mode of electrodeposition, current density and saccharin on the microstructure and hardness of electrodeposited nanocrystalline nickel coatings'. Surface \& Coatings Technology, 2016, 291, 130-140. doi:

$\underline{10.1016 / j . s u r f c o a t .2016 .02 .024 . ~}$ 